\title{
New Tools for an Old Disease: Endovascular Treatment for Varicose Veins
}

\author{
Zia Ur Rehman
}

Endovenous methods of treating varicose veins have generated some interest in the field of 'Phlebology' which was rather ignored until now. Varicose veins are not only cosmetically disfiguring; but can also be a source of chronic leg pain, disabling swelling, and nonhealing ulcers. They frequently affect patient's healthrelated quality of life. ${ }^{1}$ They involve more than $30 \%$ of adult population. 2 The signs of chronic venous insufficiency range from mild inflammation to complicated ulcers. $^{3}$ Traditional treatment is surgery, which involves disconnection of saphenofemoral and/or saphenopopliteal junctions with or without stripping of the superficial axial vein. Surgery is usually performed under general or spinal anaesthesia. It requires hospitalisation, associated with wound-related complications and phenomenon of neovascularisation / recurrence as a result of groin dissection.

Newer minimal invasive methods are being introduced since 2000.1 They can be performed as day-care procedure under local anaesthesia. The success and recurrence rates are at least similar, if not more favourable, compared to open surgery. 4 In these procedures, either great or the short saphenous vein is ablated. As the groin is not dissected, patients do not suffer from wound-related complications and the phenomenon of neovascularisation.

Endovenous ablation is performed either by thermal or non-thermal means. In thermal ablation, inner lining of veins is damaged to induce local inflammation and fibrosis. ${ }^{5}$ This leads to vein occlusion and abolishes the superficial reflux. Endovenous thermal ablation (EVTA) includes radio-frequency ablation (RFA), endovenous laser ablation (EVLA), ultrasound-guided foam sclerotherapy (USGFS), steam ablation and microwave sclerotherapy. Indications of each modality differ little from each other. Because of rigidity and size of disposables, straight saphenous veins with diameter of at least $3 \mathrm{~mm}$ are more suitable for EVLA and RFA. Steam ablation may be suitable for recurrence after

Department of Surgery, Aga Khan University Hospital, Karachi, Pakistan

Correspondence: Dr. Zia Ur Rehman, Section of Vascular Surgery, Department of Surgery, Aga Khan University

Hospital, Stadium Road, Karachi, Pakistan

E-mail: ziaur.rehman@aku.edu

Received: October 18, 2018; Accepted: January 11, 2019 stripping, as steam may find its way easier into side branches and loops. USGFS can be the first line treatment choice for tortuous recurrence after stripping. 1,4

Side effects of endothelial ablation are minimal such as pain and bruising. They are generally mild and allow to return normal activity next day.1,3,4 In the manufacturer's registry, over a period of five years, the complications are low with <1:2500 deep venous thrombosis (DVT), $<1: 1000$ pulmonary embolism and <1:50000 death. 6 However, the numbers are higher according to insurance companies databases, revealing thrombotic complications in more than 130,000 patients within 30 days after intervention for varicose veins. The estimated risk for DVT was $4.4 \%$ for RFA and $3.1 \%$ for EVLA; the risk of pulmonary embolism was $0.3 \%$ for both methods. 7

Both EVLA and RFA have similar indications; and more or less, same steps except for the use of different energy sources and catheters. ${ }^{8}$ Both of these procedures are performed under tumescent anaesthesia, infiltrated into the perivenous space. Its main aim is to provide analgesia, local compression and heat sink to prevent overlying skin from burn injury. The procedure to access the target vein(s) and the anaesthesia techniques are similar. Under ultrasound guidance, the long saphenous vein is punctured around knee joint level and a sheath is placed. The special catheter is placed through it and moved forward to the saphenofemoral junction. Its tip is placed distal to the junction. This is to mimimise the risk of deep venous thrombosis, which is significantly more if the catheter tip is at the junction. Tumescent anaesthesia is infiltrated around the catheter. The distal segment of RFA catheter is specially designed to deliver radiation energy to vein and damages its lining. Every 7-cm segment is treated step-wise, and the catheter is pull out. Compression in the form of special dressing is provided. The patient is mobilised soon after the procedure. Usually, compression in the form of stocking is provided for two weeks. Seven randomised controlled trials reported between 2002 and 2011, compared endovenous ablation therapy with conventional open surgery and most reported short-term safety and efficacy outcomes. 8 The follow-ups ranged from 1 week to 3 years. ${ }^{8}$ In two randomised control trials, reporting results are upto 2 years; and one RCT reporting results at 3 years. 9 EVLA and RFA are recommended by American Venus Forum and British National Institute for 
Health and Clinical Excellence, as first line of treatment of saphenous veins with reflux. ${ }^{10}$ The treatments had been found with speedy recovery and less recurrence of venous ulcers than the conventional surgery. ${ }^{10}$ There is evidence that it is more economical than open surgery. ${ }^{10}$

Endovenous steam ablation is relatively less frequently used. It works by denaturing the vein lining and its contents with steam at a temperature of maximal $120^{\circ} \mathrm{C}$. This also requires tumescent anaesthesia. The procedural details are more or less the same as of RFA, but its catheter is more flexible and thinner. Puffs of the steam are delivered at every centimeter, while the catheter is pulled out.

In USGFS, usually sodium tetradecyl sulfate is used as sclerosing agent. This causes local endothelial damage, which induces inflammation; and ultimately leads to vein sclerosis and ablation of reflux. It does require multiple sessions and associated with higher rate of recurrence. A randomised controlled trial compared four modalities of treating varicose veins: EVLA, RFA, USGFS and surgical stripping for great saphenous veins. At 1-year follow-up, UGFS was associated with higher technical failure $(16.3 \%)$ compared to other modalities $(p<0.001) .11$

Endovenous Microwave Ablation (EMA) works by generating radio-frequency energy. It generates radiofrequency energy with the MICROTAZE OT-110 M machine. In a randomised controlled trial comparing conventional surgery to EMA for the treatment of great saphenous vein incompetence, EMA was shown to be efficacious with $97 \%$ vein occlusion rate, and the EMA group, with no recurrence in the surgery group after 1-year follow-up. ${ }^{12}$

The challenge with these endovenous thermal ablation procedures is administration of tumescent anaesthesia. This is time-consuming and painful step of the procedure, associated with side effects like bruising. There has been a demand for non-tumescent, non-thermal techniques.

These newer methods are as effective as thermal ablation methods and do not need tumescent anaesthesia. These include mechano-chemical ablation (MOCA) and cyanoacrylate embolization (CAE).

MOCA is a catheter-based system in which endothelium is physically damaged by stripping off the vein, using a rotating wire at its tip while liquid sclerosant (usually sodium tetradecyl sulfate) is administered concomitantly. Preliminary experiences with MOCA showed good results and less post-procedural pain. ${ }^{13,14}$ It is unknown whether this treatment results in durable vein occlusion, in the long-term.

In CAE, glue is placed in the vein lumen as it prevents superficial reflux. Both MOCA and CAE are better compared to thermal-based procedures in terms of patient discomfort, risk of nerve injury, and hematoma formation. ${ }^{15,16}$ There are even prospective, multicenter randomised clinical trial underway to asses which modality is better. ${ }^{17}$

In conclusion, over the last decade the treatment of varicose veins has transformed from open surgery to endovenous ablation with comparable results.1,4,5 Endovenous ablation is commonly offered using radiofrequency ablation or laser ablation, using tumescent anaesthesia with minimal morbidity.6,8 Newer nontumescent, non-thermal methods are developed, which are thought to be associated with even better results. ${ }^{15-17}$ Only long-term follow-up will show where these minimally invasive methods stand in the therapeutic armamentarium for the treatment of "one of the oldest disease of human race".

\section{REFERENCES}

1. Proebstle $T$, van den Bos R. Endovascular ablation of refluxing saphenous and perforating veins. Vasa 2017; 46:159-66.

2. Evans CJ, Fowkes FG, Ruckley CV, Lee AJ. Prevalence of varicose veins and chronic venous insufficiency in men and women in the general population: Edinburgh vein study. $J$ Epidemiol Community Health 1999; 53:149-53.

3. Attaran RR. Latest innovation in the treatment of venous disease. J Clin Med 2018; 7:E77.

4. van den Bos R, Arends L, Kockaert M, Neumann M, Nijsten T. Endovenous therapies of lower extremity varicosities: A metaanalysis. J Vasc Surg 2009; 49:230-9.

5. Belramman A, Bootun R, Lane TRA, Davies AH. Endovenous management of varicose veins. Angiology 2018:3319718780049.

6. Malgor RB, Gasparis AP, Labropoulos N. Morbidity and mortality after thermal venous ablations. Int Angiol 2016; 35:57-61.

7. O'Donnell TF, Eaddy M, Raju A, Boswell K, Wright D. Assessment of thrombotic adverse events and treatment patterns associated with varicose vein treatment. J Vasc Surg Venous Lymphat Disord 2015; 3:27-34.

8. Bozoglan O, Mese B, Eroglu E, Ekerbiçer HC, Yasim A. Comparison of endovenous laser and radiofrequency ablation in treating varices in the same patient. $J$ Laser Med Sci 2017; 8:13-6.

9. Medical Advisory Secretariat. Endovascular radiofrequency ablation for varicose veins: An evidence-based analysis. Ont Health Technol Assess Ser 2011; 11:1-93.

10. Gloviczki P, Comerota AJ, Dalsing MC, Eklof BG, Gillespie DL, Gloviczki ML, et al. The care of patients with varicose veins and associated chronic venous diseases: Clinical practice guidelines of the society for vascular surgery and the American venous forum. J Vasc Surg 2011; 53(5 Suppl):2S-48S.

11. Rasmussen LH, Lawaetz M, Bjoern L, Vennits $B$, Blemings $A$, Eklof $B$. Randomized clinical trial comparing endovenous laser ablation, radiofrequency ablation, foam sclerotherapy and surgical stripping for great saphenous varicose veins. $\mathrm{Br} \mathrm{J}$ Surg 2011; 98:1079-87.

12. Yang L, Wang XP, Su WJ, Zhang Y, Wang Y. Randomized clinical trial of endovenous microwave ablation combined with high ligation versus conventional surgery for varicose veins. Eur J Vasc Endo vasc Surg 2013; 46:473-9.

13. Elias S, Raines JK. Mechanochemical tumescentless endovenous ablation: Final results of the initial clinical trial. Phlebology 2012; 27:67-72. 
14. van Eekeren RR, Boersma D, Elias S, Holewijn S, Werson DA, de Vries JP, et al. Endovenous mechanochemical ablation of great saphenous vein incompetence using the ClaviVeinTM device: A safety study. J Endovasc Ther 2011; 18: 328-34.

15. Morrison N, Gibson K, McEnroe S, Goldman M, King T, Weiss R, et al. Randomized trial comparing cyanoacrylate embolization and radio-frequency ablation for incompetent great saphenous veins (VeClose). J Vasc Surg 2015; 61:985-94.
16. Lane T, Bootun R, Dharmarajah B, Lim CS, Najem M, Renton S, et al. A multi-centrer andomised controlled trial comparing radio-frequency and mechanical occlusion chemically assisted ablation of varicose veins - final results of the Venefit versus Clarivein for varicose veins trial. Phlebology 2017; 32:89-98.

17. Belramman A, Bootun R, Tang TY, Lane TRA, Davies AH. Mechanochemical ablation versus cyanoacrylate adhesive for the treatment of varicose veins: Study protocol for a randomised controlled trial. Trials 2018; 19:428.

$\cdots \cdot \hat{\imath} \cdot \ldots$ 